Çiğdem COŞKUN HEPCAN Şerif HEPCAN

Ege Üniversitesi, Ziraat Fakültesi, Peyzaj Mimarlığı Bölümü, 35100, İzmir / Türkiye

Anahtar Sözcükler:

Taç örtüsü analizi, düzenleyici ekosistem servisleri, hava kalitesi, Ege Üniversitesi Lojmanlar Yerleşkesi

\section{Ege Üniversitesi Lojmanlar Yerleşkesinin Hava Kalitesinin Iyileştirilmesine Yönelik Düzenleyici Ekosistem Servislerinin Hesaplanması}

\author{
Assessing Air Quality Improvement as a Regulating Ecosystem \\ Service in the Ege University Housing Campus
}

Alınış (Received): $31.08 .2016 \quad$ Kabul tarihi (Accepted): 25.11.2016

\section{ÖZET}

Yentsel yeşil alanlar hava serinletme, Isı adası etkisini azaltma, karbondioksit depolama, kirleticileri uzaklaştırarak havayı temizleme, toprağı zenginleştirme, kökleri ile toprağı havalandırma, yaban hayatı için besin ve barınma ortamı sağlama, yağış sularının yüzeysel akışa geçmesini önleme, kullanıcılara rekreasyonel ve eğitsel olanaklar sunma gibi birçok ekosistem servisi/hizmeti sağlamaktadır. Ege Üniversitesi Lojmanlar Yerleșkesi Bornova İlçesinde bulunan bütünlüğünü koruyan, geniş yeşil alanlardan biridir. Bu araştırmada Lojmanlar Yerleşkesindeki taç örtüsü, hava kalitesinin iyileştirilmesine yönelik düzenleyici ekosistem servisleri açısından ne düzeyde yararlar sağlamaktadır? sorusuna cevap aranmıştır. Bu amaçla taç örtüsünce hava kirliliğine neden olan gazların atmosferden uzaklaştırılması ile atmosferik karbonun yakalanması ve depolanmasına yönelik analizlerinin bir arada yapılmasına olanak sağlayan I-tree canopy modeli kullanılmıştır. Sonuçlar yüzde 48'i taç örtüsüyle kaplı olan lojmanlar yerleşkesinin bir yılda 321.57 ton karbon yakaladığı ve 8107.86 ton karbon depoladığı belirlenmiştir. Bunun yanı sıra bitki taç örtüsünce bir yılda atmosferden $28.70 \mathrm{~kg}$ Karbon monoksit (CO), $143.85 \mathrm{~kg}$ Nitrojen dioksit $\left(\mathrm{NO}_{2}\right), 1.58$ ton $\mathrm{Ozon}\left(\mathrm{O}_{3}\right), 90.6 \mathrm{~kg}$ Kükürt dioksit $\left(\mathrm{SO}_{2}\right), 69.61 \mathrm{~kg}$ PM2.5 ve $479.90 \mathrm{~kg}$ PM10 parçacık madde uzaklaştırıldığı hesaplanmıştır.

\section{ABSTRACT}

U

rban green areas provide many valuable ecosystem services such as regulating storm water infiltration, improving air quality, reducing urban heat island effects, provisioning food and habitats for many species, providing recreation and nature education for the city dwellers. Housing campus of Ege University is one of the largest and the most intact urban green patches in the Bornova district. This study aimed to answer the research question that is at what level air quality improvement as a regulating ecosystem service has been provided by the canopy cover of the Ege University housing campus? For this purpose, l-tree canopy tool was used to analyze the removal of atmospheric air pollutants, and carbon sequestrated and stored by canopy cover of the housing campus. The results revealed that tree and shrub canopy covers $48.3 \%$ of the campus. While about 321.57 tons of Carbon Dioxide was sequestered annually, 8107.86 tons of Carbon Dioxide was stored by plants. In addition, it was calculated that these plants removed about $28.70 \mathrm{~kg}$ of Carbon Monoxide (CO), $143.85 \mathrm{~kg}$ of Nitrogen Dioxide $\left(\mathrm{NO}_{2}\right), 1.58$ tons of Ozone $\left(\mathrm{O}_{3}\right), 90.6 \mathrm{~kg}$ of Sulfur Dioxide ( $\left.\mathrm{SO}_{2}\right), 69.61 \mathrm{~kg}$ PM2.5 and $479.90 \mathrm{~kg}$ PM10 particulate matter per year. 


\section{GíRiş}

Bitkiler, özellikle ağaçlar gölge oluşturma, hava serinletme, ISI adası etkisini azaltma, $\mathrm{CO}_{2}$ depolama, kirleticileri uzaklaştırarak havayı temizleme, yaprak dal meyve vb. organik materyaller ile toprağı zenginleştirme, kökleri ile toprağı havalandırma, yaban hayatı için besin ve barınma ortamı sağlama, yağış sularının yüzeysel akışa geçmesini önleme, yeraltı su kaynaklarını besleme, rüzgâr ve yağış erozyonunu azaltma, gürültü filtreleme, enerji tüketimini azaltma ve arazilerin emlak değerini arttırma gibi birçok işleve sahiptir. Aynı zamanda ekosistem servisleri/hizmetleri olarak tanımlanan bu işlevler bitkilerin türlerine, yaşlarına ve bulundukları ortamın özelliklerine bağlı olarak değişiklik gösterir. Örneğin, parkta bulunan bir ağaç, bir yol ağacına kıyasla atmosferden çok daha fazla kirletici toplar. Aynı şekilde parktaki ağaç daha fazla oranda karbondioksit tutar (Forman, 2014).

Ekosistemlerin doğrudan ya da dolaylı olarak sağladığı servisler tedarik servisleri, düzenleyici servisler, habitat ya da destekleyici servisler ve kültürel servisler olmak üzere dört grup altında sınıflandırılır (MEA, 2005).

$\mathrm{Bu}$ araştırmaya konu olan düzenleyici servisler, ekosistemlerin kontrol ettiği doğal süreçlerden sağlanan yararlardır. Hava ve toprak kalitesinin iyileştirilmesi, iklim regülasyonu, taşkın ve heyelan gibi doğal afetlerin etkisini azaltma, hastalık kontrolü, suyun filtre edilmesi, atık yönetimi, polenizasyon/tozlaşma, biyolojik parçalanma ya da zararlı türlerin kontrolü düzenleyici hizmetler arasında sayılabilir (MEA, 2005).

Kentsel yeşil alanlar, ekosistem servisleri bağlamında vazgeçilmez öneme sahip mekanlardır (Bolund and Hunhammar, 1999; Forman, 2008; Derkzen et al., 2015). Maalesef günümüz kentlerinde büyük ölçüde bir süsleme aracı olarak kullanılan kentsel yeşil alanlar çoğu zaman yapılaşmış alanlar arasında kalan küçük, yalıtılmış ve düzensiz dağılım gösteren parseller şeklindedir (Steiner, 2011; Hepcan, 2013). Forman (2008), günümüzde kentsel peyzajlarda geniş ve bütünlüğünü koruyan koruluklara rastlamanın oldukça güç olduğunu, ancak bu alanların bulunduğu kentlere çok önemli ekolojik katkılar sağladığını belirtmektedir.

Kentsel yeşil alanların bu negatif durumu Türkiye ve İzmir kenti içinde çok farklı değildir. Örneğin İzmir kenti genelinde kentsel yeşil alan miktarı \% 10'un altında olup, küçük ve düzensiz dağılım gösteren bir yapıdadır (Coşkun Hepcan ve ark., 2013).

Kentsel yeşil alanların yukarıda adı geçen yetersizliği ve düzensizliği nedeniyle, kentlerde kirleticiler artmakta, hava kalitesi düşmekte, kentsel ısı adası etkisi artmakta, kentsel yaşama kalitesi düşmektedir. Aynı zamanda kentsel yeşil alanların bu durumu ekolojik sistemlerin işleyişine de bir hayli zarar vermektedir.

Ülkemizde Ulusal Hava Kalitesi İndeksi, EPA (ABD Çevre Koruma Ajansı) Hava Kalitesi İndeksi temelinde oluşturulmuştur. İndekste, karbon monoksit (CO), kükürt dioksit $\left(\mathrm{SO}_{2}\right)$, azot dioksit $\left(\mathrm{NO}_{2}\right)$, ozon $\left(\mathrm{O}_{3}\right)$ ve partikül maddeler (PM2.5-PM10), hava kirleticiler olarak tanımlamakta, hava kalitesine ilişkin ölçümlerde bu parametreler dikkate alınmaktadır (Çevre ve Şehircilik Bakanlığı, 2016).

Atmosferdeki kirleticiler insan sağlığına olduğu kadar ekolojik sistemlerin işleyişine de zarar vermektedir (Curtis et al., 2006). Örneğin; CO omurgalı canlılarda kanda taşınan oksijen seviyesini azaltır (Forman, 2014; Güvendik ve Yılmaz, 2003). $\mathrm{CO}_{2}$ sera etkisi oluşturarak hava sıcaklığının yükselmesine neden olur (Forman, 2008). Çoğunlukla fosil yakıtların yanması sonucunda ortaya çıkan $\mathrm{SO}_{2}$ (Agren, 1991) insanlarda solunum sistemi rahatsızlıklarına yol açar, bitkilerde ise yaprak dokularına zarar vererek ölümlere neden olur (Moran and Mogan, 1994). Benzer şekilde havadaki $\mathrm{O}_{3}$ seviyesinin artması, insanlarda solunum sistemi ve kalp rahatsılıklarının oluşmasına, bitki örtüsünde büyüme hızının azalmasına neden olmaktadır (Forman, 2008; Çevre ve Şehircilik Bakanlığı, 2014). Partikül madde havada asılı halde bulunan katı, sıvı veya katı çekirdeğin etrafında sıvı ile çevrili olan parçacıkların bir karışımıdır. Egzoz gazı, orman yangını, sigara dumanı, volkanik gazlar ile katı ve sıvı bileşenlerin atmosfere karışması sonucu oluşan bu parçacıklar çap büyüklüklerine göre adlandırılır. PM2,5 2,5 m'den küçük partiküllerin kütlesini, PM10, boyutları 2.5-10 mikron arasında değişen partikülleri tanımlar. İnsan sağlığı açısından en tehlikeli maddeler arasında sayılan parçacık maddelerin solunum sistemi hastalıkları, kalp rahatsızlıkları ve kansere neden olduğu bilinmektedir (Yatkın ve Bayram, 2007; Kardeşoğlu ve ark., 2011). Parçacık maddeler aynı zamanda yaprak ve bitki gelişimini geriletir, liken ve yosunların ölümüne yol açar (Marsh, 2010).

Bitkiler fizyolojik özellikleriyle birçok kirleticiyi depolama, filtre etme ve başka formlara dönüştürme yeteneğine sahiptir. Örneğin, $\mathrm{CO}_{2}$ fotosentez işleminde kullanılır ve ayrıca odunsu bitkilerin bünyelerinde depolanır. $\mathrm{SO}_{2}$ yapraklar tarafından absorbe edilerek ortamdan uzaklaştırılır (Smith, 1990). Parçacık maddeler ise filtre edilerek yaprak yüzeyinde toplanır ve yağışla birlikte toprağa iletilir. Farklı tür, form ve boyda bitki katmanlarından oluşan bitki örtüsünün parçacık maddeleri filtre etme yeteneği fazladır (Spirn, 1984).

Kentsel yeşil alanlardan sağlanan ekosistem servislerinin hesaplanmasına yönelik bilimsel çalışmalar son dönemlerde ağırlık kazanmaya başlamıştır (Brack, 
2002; Nowak, 2000). Ahern et al., (2014), ekosistem servislerinin ölçülebilir matematiksel yöntemler kullanılarak hesaplanması önemini vurgulamaktadır. Bitki taç örtüsünü dikkate alarak hava kalitesinin iyileştirilmesine yönelik düzenleyici ekosistem servislerinin hesaplanmasında kullanılan I-tree canopy modeli bunlardan biridir.

Araştırma alanı olan Ege Üniversitesi Lojmanlar Yerleșkesi, Bornova'nın en geniş bitkilendirilmiş yeșil alanlarından biridir. Sahip olduğu fıstık çamı koruluğu ve zeytinliklerle bitki örtüsü açısından ilçedeki diğer kentsel yeşil alanlardan farklı karakterdedir. Bu çalışmada; Ege Üniversitesi Lojmanlar Yerleşkesinde bulunan bitki taç örtüsü hava kalitesinin iyileştirilmesine yönelik düzenleyici ekosistem hizmetleri açısından ne düzeyde yararlar sağlamaktadır? sorusuna cevap aranmıştır.

\section{MATERYAL ve YÖNTEM}

Araştırma materyalini araştırma alanı ve 2014 tarihli WorldView2 (Pan+MS bundle) (50cm yersel çözünürlük) uydu görüntüsü oluşturmaktadır.

Araştırma alanı olarak tanımlanan Ege Üniversitesi Lojmanlar Yerleşkesi, Bornova ilçesinin doğusunda, merkez kampüsün ve Ankara asfaltının kuzeyinde yer almaktadır. Ege Üniversitesi konuk evi, Güneş Enerjisi Enstitüsü ve personel lojman binaları, fıstık çamı koruluğu ve zeytinlikleri içeren yerleşke 54.47 ha büyüklüğündedir. Yerleşkede yer alan 2200 m uzunluğundaki yürüyüş parkuru üniversite personelinin yanı sıra ve yakın çevrede yaşayan halk tarafından yürüyüş, koşu ve bisiklete binme amacıyla haftanın her günü aktif olarak kullanılmaktadır (Şekil $1-2)$.

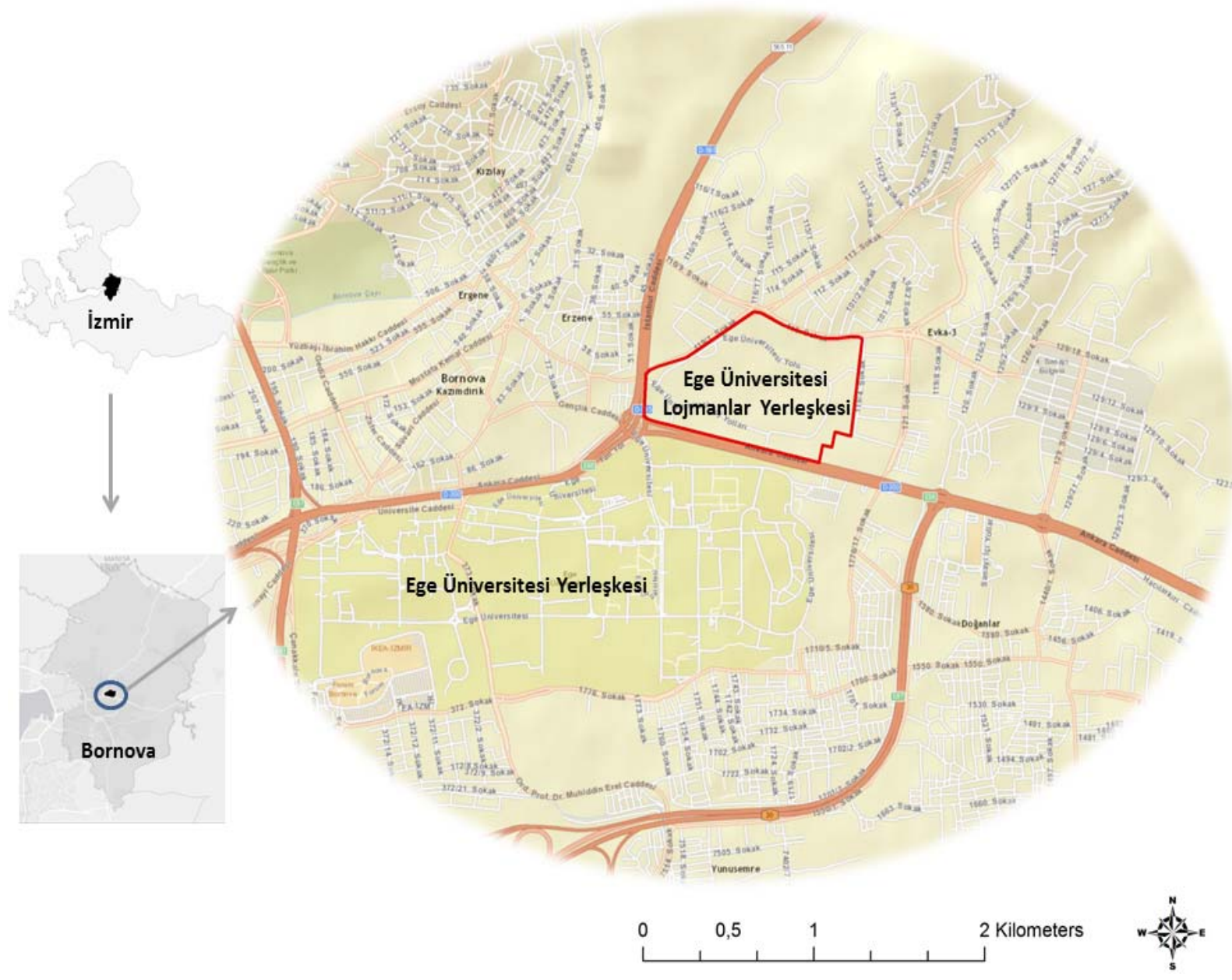

Sekil 1. Araştırma alanı

Figure 1. The study area 


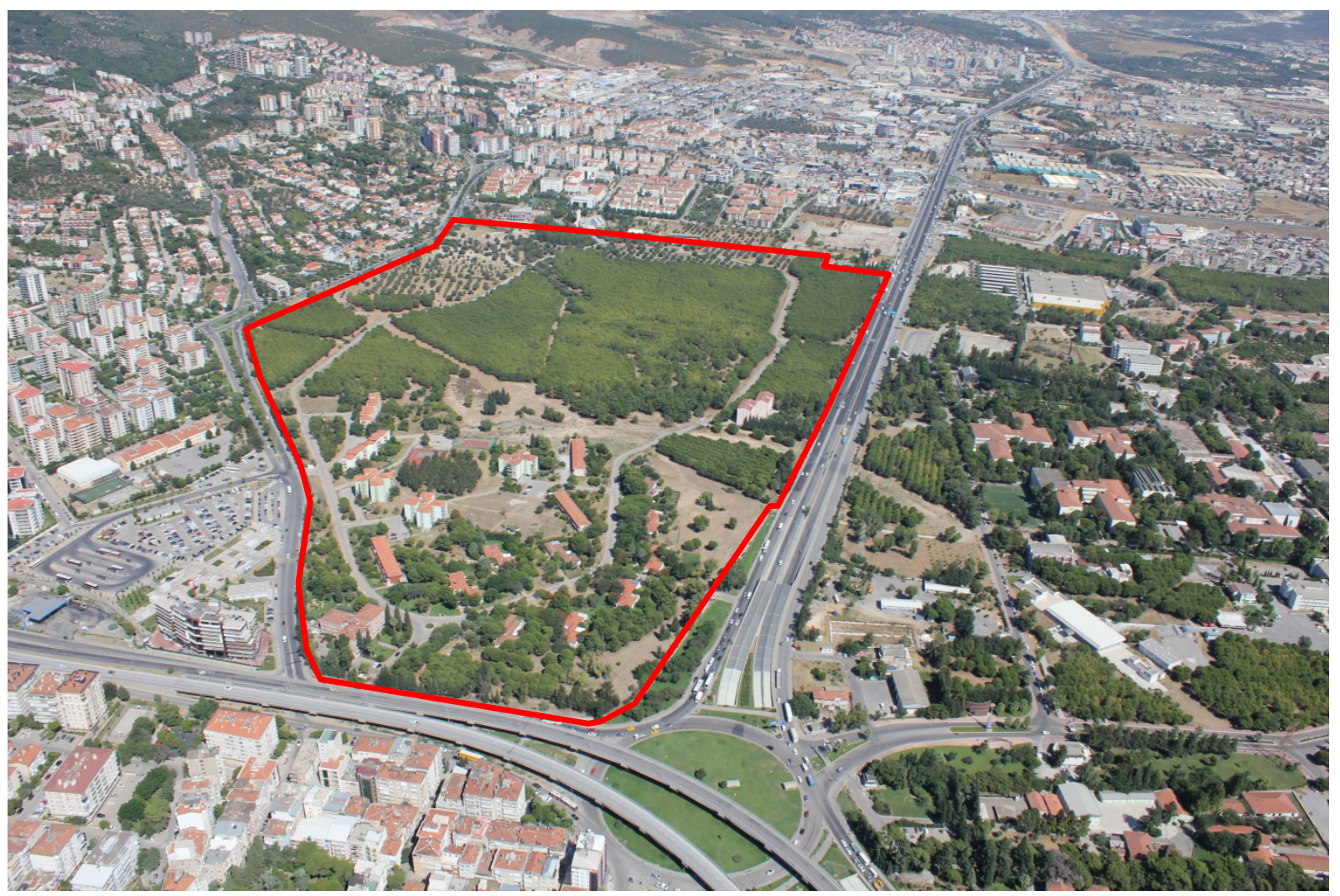

Şekil 2. Lojmanlar yerleşkesinin genel görünümü

Figure 2. The view of University housing campus

Yerleşkede 23.88 ha büyüklüğündeki bir alanı kaplayan fıstık çamı koruluğu 1983-1984 yıllarında Ege üniversitesi ormanı oluşturmak amacıyla Orman Genel Müdürlüğü'nün katkılarıyla fıstık çamı (Pinus pinea) plantasyonu yapılarak oluşturulmuştur. Fıstık çamı ağaçları günümüzde yaklaşık 15 metre boy ve 5-6 m taç genişliğine sahiptir. Yerleşkenin Kuzey ve Batısında bulunan zeytinlikler ise yaklaşık 10.77 ha büyüklüğündedir (Şekil 2).

Ege Üniversitesi Lojmanlar Yerleşkesindeki taç örtüsünün analiz edilmesinde Birleşik Devletler Tarım Departmanı Orman Servisi (USDA-United States Department of Agriculture Forest Service) tarafından geliştirilen, taç örtüsünün hava kalitesinin iyileştirilmesine yönelik sağladığı düzenleyici ekosistem hizmetlerinin hesaplanmasında kullanılan I-tree canopy modeli kullanılmıştır.

I-tree canopy modeli bir alandaki arazi örtüsü tiplerinin dağılımına yönelik hızlı ve kolay bir şekilde doğruluk oranı yüksek istatistiki tahminler geliştiren bir araçtır. I-tree yazılımının bir modülü olan bu model aynı zamanda, taç örtüsüne ilişkin değerleri dikkate alarak, hava kirliliğine neden olan gazların $\left(\mathrm{CO}, \mathrm{NO}_{2}, \mathrm{O}_{3}, \mathrm{SO}_{2}, \mathrm{PM} 2.5, \mathrm{PM} 10\right)$ bitkilerce atmosferden uzaklaştırılması, atmosferik karbonun yakalanması ve depolanmasına yönelik değerler ile bu hizmetlerin ekonomik değerlerine yönelik tahminler hesaplar. Model, kentsel peyzajlardaki orman vejetasyonlarının yönetim çalışmaları kapsamında ağaç taç örtüsü büyüklüğü ve taç örtüsünde meydana gelen zamana bağlı değişimlerin belirlenmesine yönelik analizlerde de kullanılmaktadır. Modelde araştırma alanındaki arazi örtüsü tipleri GoogleMaps uydu görüntüleri üzerinde rastgele noktalar toplanarak tanımlanır. Noktalar model tarafından atanır ve kullanıcılarca sınıflandırılır. Bu işlemde toplanan nokta sayısı kullanıcı tarafından belirlenir ve nokta sayısının fazla olması, farklı arazi örtüsü tiplerinin temsil oranını dolayısıyla modelin hassasiyetini arttırır (USDA, 2008; Marcus, 2015).

Araştırma alanının sınırları WorldView2 uydu görüntüsü kullanılarak belirlenmiş ve I-tree canopy modelinde kullanılabilecek sayısal veri formatına dönüştürülmüştür. Araştırmada I-tree canopy modeli kullanılarak, araştırma alanını tanımlayan sayısal veri 2015 tarihli Google Earth uydu görüntüsü üzerinde üç bin adet rastgele nokta seçilmiş, bu noktaların temsil ettiği arazi örtüsü (1) ağaç ve çalı (ağaç ve çalı 
vejetasyonları), (2) çim (çim alan), (3) geçirimsiz yapı (bina ve yapılar, asfalt ve beton ve kilit parke taşı kaplı yol, sıkıştırımış yol), (4) açık alan (üzerinde bitki örtüsü bulunmayan toprak yüzey) ve (5) yüzey örtücü bitki (otsu bitki vejetasyonuyla kaplı alanlar) olmak üzere beş sınıf altında gruplandırılmıştır. Nokta seçiminin tamamlanmasından sonra model çalıştırılmış, lojmanlar yerleşkesindeki taç örtüsünün hava kalitesinin iyileştirilmesine yönelik düzenleyici ekosistem servisleri kapsamında sağladığı yararlar hesaplanmıştır.

\section{ARAŞTIRMA BULGULARI ve TARTIŞMA}

Analiz sonuçları Lojmanlar Yerleşkesindeki taç örtüsünün alanın yaklaşık \%50'sini kapladığını göstermektedir. Geçirimsiz yüzeyler de yerleşkenin yaklaşık \%10'unu kaplamaktadır. Standart sapma değerlerinin birin altında olması, araştırma alanındaki arazi örtüsü sınıflarında nokta dağılımlarının tüm sınıflar için eşit ağırlıkta olduğunu ifade etmektedir (Çizelge 1).

Lojmanlar Yerleşkesindeki taç örtüsü tarafından atmosferden uzaklaştırılan yıllık CO miktarı $28.70 \mathrm{~kg}$ olarak hesaplanmıştır (Çizelge 2). Bu değer örneğin Barselona kenti yeşil alanları için toplamda yıllık 5.6 ton (Chaparro and Terradas, 2009), Edinburg kenti yeşil alanları için bir tondur (Hutchings et al., 2012).

Araştırmada, Lojmanlar Yerleşkesinde bir yılda atmosferden uzaklaştırılan $\mathrm{NO}_{2}$ miktarının $143.85 \mathrm{~kg}$ olduğu belirlenmiştir (Çizelge 2). Oregon State Üniversitesi yerleşkesindeki ağaçların bir yılda atmosferden uzaklaştırdığı $\mathrm{NO}_{2}$ miktarı 2700 kg'dır (Phillips et al., 2013). Bu değer Springfield (Massachusetts) kentindeki yeşil alanlar için 18.76 ton (Bloniarz and Beals, 2014), Edinburg kenti yeşil alanları için 20 ton olarak hesaplanmıştır (Hutchings et al., 2012).

Yerleşkedeki bitki taç örtüsünün atmosferden bir yılda uzaklaştırdığı $\mathrm{O}_{3}$ miktarı 1.58 ton olarak hesaplanmışır (Çizelge 2). Avustralya'nın Unley kentinde yer alan yerleşkenin yaklaşık onda biri $(50000$ $\mathrm{m}^{2}$ ) büyüklüğündeki Ridge Park yapılan analizlerde bitki örtüsünün bir yılda $108.49 \mathrm{~kg} \mathrm{O}$ toplayabildiği belirlenmiştir (Seed Consulting Services, 2016). Buna karşlık bu değer Springfield (Massachusetts) kentindeki yeşil alanlar için 186.80 ton (Bloniarz and Beals, 2014) Londra'daki yeşil alanlar için 997 ton (Rogers et al., 2015) ve Torbay (Ingiltere) kentindeki yeşil alanlar için 22.9 tondur (Rogers et al., 2011).

Çizelge 1. I-tree canopy arazi örtüsü analiz sonuçları Table 1. I-tree canopy land cover results

\begin{tabular}{llcc}
\hline Sınıf & Tanım & Nokta Sayısı & Kapladığı oran \% ve \pm SS \\
\hline Yapı & Bina, beton-asfalt-parke taşı kaplı yol & 312 & $10.41 \pm 0.32$ \\
Açık alan & Bitki örtüsü içermeyen toprak yüzey & 444 & $14.8 \pm 0.65$ \\
Çim alan & Çim alan & 32 & $1.07 \pm 0.19$ \\
Yer örtücü & Otsu bitki örtüsü kaplı alanlar & 764 & $25.16 \pm 0.79$ \\
Ağaç & Ağaç ve boylu çalı & 1448 & $48.3 \pm 0.91$ \\
\hline
\end{tabular}

*SS- Standart sapma

Çizelge 2. I-tree canopy analiz sonuçları- taç örtüsünden sağlanan yararlara ilişkin tahminler Table 2. Itree Canopy results - Canopy benefit estimates

\begin{tabular}{lllll}
\hline Atmosferden uzaklaştırılan kirleticiler & Değer & $\mathbf{\pm S S}$ & Miktar & $\mathbf{\pm S S}$ \\
\hline CO-Karbon monoksit (yıllık) & $\$ 2.47$ & \pm 0.05 & $528.70 \mathrm{~kg}$ & \pm 1.10 \\
NO2-Nitrojen dioksit (yıllık) & $\$ 4.24$ & \pm 0.08 & $143.85 \mathrm{~kg}$ & \pm 5.99 \\
O3-Ozon (yıllık) & $\$ 221.05$ & \pm 4.18 & $1.58 \mathrm{~T}$ & \pm 0.03 \\
PM2.5-Parçacık madde $<2.5 \mu$ (yıllık) & $\$ 456.96$ & \pm 8.64 & $69.61 \mathrm{~kg}$ & \pm 2.90 \\
SO2-Kükürt dioksit (yıllık) & $\$ 0.74$ & \pm 0.01 & $90.6 \mathrm{~kg}$ & \pm 3.78 \\
PM10-2.5 $\mu$ Parçacık madde <10 $\mu$ (yıllık) & $\$ 160.48$ & \pm 3.03 & $479.90 \mathrm{~kg}$ & \pm 20.00 \\
CO2seq-Odunsu bitkilerce tutulan karbon dioksit (yıllık) & $\$ 111635.21$ & \pm 219.89 & $321.57 \mathrm{~T}$ & \pm 6.08 \\
CO2stor-Odunsu bitkilerce depolanan karbon dioksit & $\$ 293394.92$ & \pm 5554.8 & $8107.86 \mathrm{~T}$ & \pm 153.23 \\
\hline
\end{tabular}

*SS- Standart sapma

Araştırmada, Lojmanlar Yerleşkesindeki bitki örtüsünün atmosferden bir yılda uzaklaştırdığı parçacık madde miktarı 69,61 kg PM 2.5 ve $479.90 \mathrm{~kg}$ PM 10 olarak hesaplanmıştır (Çizelge 2). Oregon State ve Pensilvanya Üniversiteleri yerleşkelerinde yapılan analiz sonuçları bu araştırmanın sonuçlarıyla benzerlik göstermektedir. Pensilvanya Üniversitesi merkez yerleşkesinde $\left(0.64 \mathrm{~km}^{2}\right)$ taç örtüsünün atmosferden uzaklaştırdığı PM2.5 miktarı $47 \mathrm{~kg}$ (Bassett, 2015), Oregon State Üniversitesi kampüsündeki $\left(1.6 \mathrm{~km}^{2}\right)$ ağaçların bir yılda atmosferden uzaklaştırdığı PM10 miktarı ise 400 kg'dır (Phillips et al., 2013). Kentlerde 
havadaki parçacık maddelerin temizlenmesinde bitki örtüsünün önemini ortaya koyan birçok çalışma bulunmaktadır. Örneğin, Edinburg kentindeki yeşil alanların 28 ton (Hutchings et al., 2012), Oakville (Kanada) kentindeki yeşil alanların 50 ton (McNeil and Vava 2006), ve Torbay (Ingiltere) kentindeki yeşil alanların 18 ton PM10 parçacık maddeyi atmosferden uzaklaştırdığı belirlenmiştir (Rogers et al., 2011).

Analiz sonuçları Lojmanlar Yerleşkesindeki bitki örtüsünün atmosferden bir yılda $90.65 \mathrm{~kg} \quad \mathrm{SO}_{2}$ uzaklaştırabilecek kapasitede olduğunu göstermektedir (Çizelge 2). Oregon State Üniversitesi kampüsündeki ağaçların bir yılda atmosferden uzaklaştırdığı $\mathrm{SO}_{2}$ miktarı lojmanlar yerleşkesinden dört kat fazla olup, 400 kg'dır (Phillips et al., 2013). Bazı kentlerdeki yeşil alanlarında yürütülen çalışmalarda çok farklı sonuçlar elde edilmiştir. Örneğin, atmosferden uzaklaştırılan $\mathrm{SO}_{2}$ miktarı Springfield (Massachusetts) kentindeki yeşil alanlar için 12.82 ton (Bloniarz and Beals, 2014), Barselona kentindeki bitki örtüsü için 6.8 ton (Chaparro and Terradas, 2009), Oakville (Kanada) kentindeki ormanlık alanlar için 11.6 ton (McNeil and Vava 2006), ve Torbay (Ingiltere) kentindeki yeşil alanlar için 1.3 ton olarak hesaplanmıştır (Rogers et al., 2011).

Lojmanlar Yerleşkesindeki odunsu bitkilerce tutulan yıllık karbon $\left(\mathrm{CO}_{2}\right.$ seq) miktarı 321.57 ton, yaşamları süresince depoladığı karbon $\left(\mathrm{CO}_{2}\right.$ stor $)$ miktarı ise 8107.86 ton olarak hesaplanmıştır (Çizelge 2). Pensilvanya Üniversitesi yerleşkesinde ağaçlarca tutulan yıllık karbon miktarı 34.25 ton, depolanan toplam karbon miktarı 715.18 tondur Bassett (2015), Mountshannon (İrlanda) kentinde ekosistem servislerinin hesaplandığı $68500 \mathrm{~m}^{2}$ büyüklüğündeki bir kent parkındaki bitki örtüsünün bir yılda 4 ton karbon tuttuğu ve 116 ton karbon depoladığı belirlenmiş̧ir (Carey and Tobin, 2016). Benzer şekilde Unley kentinde yer alan (Avustralya) $50000 \mathrm{~m}^{2}$ büyüklüğündeki Ridge Park'taki bitki örtüsünün 10.08 ton karbon tuttuğu ve 342 ton karbon depoladığı belirlenmiş̧ir (Seed Consulting Services, 2016). Chicago kentindeki yeşil alanlar bir yılda 677000 ton karbon tutmakta ve 16.9 milyon ton karbon depolamaktadır (Nowak et al., 2013).

Lojmanlar yerleşkesinden sağlanan tüm bu hizmetlerin yıllık ekonomik değeri 112,481 dolar olarak hesaplanmıştır (Çizelge 2). Barcelona kenti yeşil alanlarında yürütülen bir araştırmada yeşil alanların bir yılda 305.8 ton kirleticiyi atmosferden temizlediği belirlenmiş, bunun yaklaşık ekonomik değerinin $1,245,900$ dolar olduğu belirtilmiştir (Chaparro and Terradas, 2009). Chicago kentindeki yeşil alanların
18.080 ton kirleticiyi uzaklaştırabildiği, bunun parasal değerinin 137 milyon dolar olduğu belirlenmiştir (Nowak et al., 2013).

Yerleşkedeki odunsu bitkilerin yaşadığı sürece bünyesinde karbondioksit depolamasının ekonomik değeri ise yaklaşık 293,394 dolar olarak hesaplanmıştır (Çizelge 2).

Son yıllarda kentsel yeşil alanlardaki bitki örtüsünün sağladığı farklı ekosistem servislerinin hesaplamasına yönelik bilimsel çalışmalar yoğunluk kazanmıştır (Brack, 2002; Nowak, 2000). Bu çalışmalarda bitki örtüsünün dağılımı, yaşı, fiziksel durumu, boyu, toplam yaprak yüzeyi vb. veriler kullanılmaktadır. Bu analizlerde her bir bitkiye ait envanterin çıkarılması, ekosistem servislerinin hesaplanmasında başarı oranını arttırmaktadır. Ege Üniversitesi Ziraat Fakültesi Peyzaj Mimarlığı Bölümü'nde İzmir kentindeki yeşil alanların ekosistem servislerinin belirlenmesine yönelik olarak yürütülmekte olan proje kapsamında başka yeşil alanlarla birlikte Lojmanlar Yerleşkesinin sağladığı ekosistem servislerine yönelik kapsamlı analizler yapılması planlanmaktadır. Üniversite yerleşkeleri kapladıkları alan büyüklüğü, sahip olduğu bitki örtüsü, kullanımlar ve kullanıcı yoğunluğu açısından kentsel yeşil alanların birçoğundan farklılık göstermektedir. Bu proje kapsamda farklı karakterdeki yeşil alanların ekosistem servislerine olan katkılarının karşılaştırılması mümkün olacaktır.

Araştırma kapsamında sadece hava kalitesinin iyileştirilmesine yönelik düzenleyici ekosistem servisleri hesaplanmış, yerleşkedeki taç örtüsünün yağış suyu toplama, taşkın kontrolü, biyolojik parçalanma gibi düzenleyici servisler, çam fıstığı ve zeytin üretimi gibi tedarik servisleri, yabanıl türlere habitat oluşturma gibi destekleyici servisler ve rekreasyonel kullanımlar gibi kültürel servisleri içeren ekosistem servisleri hesaplanmamıştır. Bu servislerin yine devam eden proje kapsamında hesaplanması planlanmaktadır.

I-tree canopy modeli, düzenleyici ekosistem servislerinin ve bu servislerin ekonomik değerlerinin hesaplanmasında kullanılan, hızlı sonuç veren, kullanışlı ve basit bir araçtır. Ağırlıklı olarak Amerika Birleşik Devletleri'nde kullanılsa da Ingiltere, Kanada, Avustralya ve İsviçre gibi birçok farklı ülkede uygulanmaktadır. Elde edilen sonuçlar yeşil alan ve bitkilerin sağladığı yararlara ilişkin net veri sağlamaktadır. Model, ülkemiz ulusal Hava Kalitesi Indeksinde tanımlanan (Çevre ve Şehircilik Bakanlığı, 2016) beş temel kirleticiye ait indeks değerlerini hesaplamaya olanak sağlamaktadır. Modelin ülkemizde 
kullanımı (diğer ülkelerde olduğu gibi) araştırmaya konu olan ve modelde referans alınan kentlerin iklim, hava kirliliği ve bitki örtüsü verilerinin karşılaştırılabilir olduğu durumda uygundur.

I-tree canopy modelinin hassasiyeti, analizde seçilen nokta sayısının fazla olmasıyla doğru orantıdır. Araştırmada, $0.54 \mathrm{~km}^{2}$ büyüklüğündeki Lojmanlar Yerleşkesinde 3000 adet nokta tanımlanmıştır. Bu rakam, aynı modelin kullanıldığı benzer çalışmalar dikkate alındığında, kabul edilebilir olarak tanımlanan nokta sınırının oldukça üzerindedir. Örneğin, 33,6km² büyüklüğündeki bir alana yayılmış olan Atlantic Beach (Florida) kentindeki ağaç taç örtüsünün analiz edildiği çalışmada toplamda 1000 adet nokta tanımlanmıştır (Marcus, 2015). Benzer şekilde Avustralya'da 139 adet yeşil alanın taç örtüsünün analiz edildiği araştırmada her bir alan için 1000 adet nokta atanmıştır (Jacobs et al., 2014).

Ekosistem servislerinin hesaplanmasına yönelik bilimsel araştırmaların büyük bölümü doğal ve kırsal peyzajlardaki ekosistemleri konu alan, bölgesel ya da ulusal ölçekli çalışmalar olup, kentsel yeşil alanlardan sağlanan ekosistem servislerine yönelik çalışmalar oldukça sınırlıdır (Derkzen et al., 2015; GomezBaggethun and Barton, 2013). Benzer şekilde ülkemizde ekosistem servislerinin hesaplanmasına yönelik araştırmalar Düzlerçamı ormanları (Balkız, 2015), İstanbul Ömerli Havzası (Albayrak, 2012) ve Sultan Sazlığı Milli Parkı (Aygün ve Yeşil Akça, 2012) gibi ağırlıklı olarak kırsal peyzajlarda yürütülmektedir. Bu çalışma, kentsel yeşil alanların ekosistem servislerinin hesaplanması açısından özgün çalışmalardan biridir.

Kentlerde tercihen büyük ve yaşlı ağaçlardan oluşan yoğun bir bitki dokusuna sahip geniş yeşil alanların yapılan analiz ve hesaplamalarla ekolojik açıdan öneminin anlaşılması, bu alanların korunması, yönetilmesi açısından önem taşımaktadır. Bu yaklaşım yeşil alan planlaması ve tasarımına rehber olabilir.

\section{KAYNAKLAR}

Albayrak, I. 2012. Ekosistem servislerine dayalı havza yönetim modelinin İstanbul-Ömerli havzası örneğinde uygulanabilirliği, Doktora Tezi, İTÜ Fen Bilimleri Enstitüsü.

Agren, C. 1991. EMEP report, MCS-W 1/91 Norway.

Ahern, J., Cilliers, S. and Niemela, J. 2014. The concept of ecosystem services in adaptive urban planning and design: a framework for supporting innovation, Landscape and Urban Planning, 125: 254259. http://dx.doi.org/10.1016/j.landurbplan.2014.01.020

Aygün, M ve Yeşil Akça, G. 2012. T.C. Orman ve Su İşleri Bakanlığı bakanlığımız ve bağlı kuruluşlarınca yürütülen Ar-Ge nitelikli projeler,
Bunun yanı sıra bu analizlerden elde edilen veriler kentsel yeşil alanlardan sağlanan ekosistem hizmetlerinin arttırıması için alınabilecek önlemlerin belirlenmesinde kullanılabilir. Örneğin, taç örtüsündeki değişimlerin bu alanlardan sağlanan ekosistem hizmetlerini ne şekilde etkileyebileceği planlama ve yönetim uygulamalarını yönlendirebilir (Seed Consulting Services, 2016).

\section{SONUÇ}

Forman (2008), geniş korulukların kent ekolojisi için önemini vurgulamaktadır. Bu araştırmadan elde edilen bilimsel bulgularlar, bu görüşü desteklemektedir.

(Brack, 2002), geniş taç örtüsüne sahip büyük ağaçlardan sağlanan $\mathrm{CO}_{2}$ tutma ve depolama, atmosferdeki kirleticileri toplama, yağış suyunun yüzeysel akışa geçmesini yavaşlatma gibi ekosistem servislerinin daha fazla olduğunu belirtmektedir. Lojmanlar Yerleşkesindeki taç örtüsünden sağlanan hava kalitesinin iyileştirilmesine yönelik düzenleyici ekosistem hizmetlerinin belirlenmesinin amaçlandığı bu araştırmanın sonuçları, yerleşkedeki geniş ve sık dokulu taç örtüsünün bir yılda toplam 324.47 ton zararlı kirleticinin atmosferden uzaklaştırılması ve yaşamları boyunca 8107.86 ton $\mathrm{CO}_{2}{ }^{\prime}$ in depolanması yoluyla kente önemli ekolojik katkılar sağladığını göstermiştir. Şüphesiz bu Bornova ilçesinde tek bir alandır ve benzer karakterdeki diğer kentsel yeşil alanların sağladığı katkılarla birlikte bu değerler artacaktır. Ancak unutulmamalıdır ki yerleşkenin geniş ve büyük ölçüde bütünlüğünü koruyan bitki dokusu burada önemli rol oynamıştır. Bu özellikleriyle Lojmanlar Yerleşkesi hem Bornova ilçesindeki kentsel açık yeşil alanların değerli bir bileşenidir, hem de nitelikleri itibarıla ekosistem servisleri açısından örnek bir yeşil alandır. Bu nedenle yapılaşma baskısına karşı bitki dokusu ve açık-yeşil alan varlığıyla mutlaka hassasiyetle korunmalıdır. www.milliparklar.gov.tr/korunanalanlar/belgeler/tescil.pdf, Erişim: 21 Şubat 2016.

Balkız, Ö. 2015. Ekosistem hizmetleri ve havza yönetimi, http://suyonetimi.ormansu.gov.tr/Libraries/su/EkosistemHizmetleri _OzgeBalkiz_20151216.sflb.ashx, Erişim: 21 Şubat 2016.

Bassett, C.G. 2015. The environmental benefits of trees on an urban university campus, Master of Environmental Studies Capstone Projects. 66. p.

Bloniarz, D. and Beals, T. 2014. I-tree canopy assessment to Springfield MA, http://www.regreenspringfield.org/, Accessed July, 20, 2016. 
Bolund, P. and Hunhammar, S. 1999. Ecosystem services in urban areas, Ecological Economics, 29: 293-301.

Brack, C.L. 2002. Pollution mitigation and carbon sequestration by an urban forest. Environmental Pollution, 116:195- 200.

Carey, B. and Tobin, B. 2016. Ecosystem services provided by mountshannon village trees, https:/static.rasset.ie/documents/ radiol/mountshannon-ecosystem-services-provided-bymountshannon-village-june-2016.pdf, Erişim 20 Temmuz 2016.

Chaparro, L. and Terradas, J. 2009. Ecological services of urban forest in Barcelona. Centre de Recerca Ecologica i Aplicacions Forestals, p. 103.

Coşkun Hepcan, Ç., Özeren, M. ve Hepcan, Ş. 2013. İzmir için ekolojik açıdan sürdürülebilir bir kent gelişim senaryosu, TMMOB İzmir 2. Kent Sempozyumu Bildiriler Kitabı, TMMOB Izmir 2. Kent Sempozyumu Bildiriler Kitabı - Kentine Sahip Çık, 28- 30 Kasım 2013: 803-811.

Curtis, L., Rea, W., Smith-Willis, P., Fenyves, E. and Pan, Y. 2006. Adverse health effects of outdoor in pollutants, Environmental International, 32: 815-830.

Çevre ve Şehircilik Bakanlığı, 2014. Yer seviyesi ozon kirliliği bilgi notu, T.C. Çevre ve Şehircilik Bakanlığı Çevre Yönetimi Genel Müdürlüğü, s.3.

Çevre ve Şehircilik Bakanlığı, 2016. Çevre ve Şehircilik Bakanlığı hava kalitesi izleme istasyonları web sitesi, http://www.havaizleme.gov.tr/hava.html, Erişim 20 Temmuz 2016.

Derkzen, M.L., Van Teeffelen, A.J.A. and Verburg, P.H. 2015. Quantifying urban ecosystem services based on highresolution data of urban green space: an assessment for Rotterdam, the Netherlands, Journal of Applied Ecology, 52: 1020-1032.

Forman, R.T.T. 2008. Urban regions: ecology and planning beyond the city, NY Cambridge University Press, p. 408. ISBN-13: 9780521670760

Forman, R.T.T. 2014. Urban ecology science of cities, Cambridge University Press, p. 462. ISBN-13: 978-052118824.

Gomez-Baggethun, E. and Barton, D.N. 2013. Classifying and valuing ecosystem services for urban planning, Ecological Economics, 86: 235-245.

Güvendik G. ve Yılmaz A. 2003. Egzos kirliliğine maruz kalan kişilerde kan karboksihemoglobin düzeyi. Ankara Eczacılık Fakültesi Dergisi, 32: 213-219.

Hepcan, Ş. 2013. Analyzing the pattern and connectivity of urban green spaces: a case study of Izmir, Turkey, Urban Ecosystems, 16: 279-293, DOI:10.1007/s11252-012-0271-2.

Hutchings, T., Lawrence, V. and Brunt, A. 2012. Estimating the ecosystem services value of Edinburgh's trees, The Research Agency of Forest Commission, p. 45.

Kardeşoğlu E., Yalçın M. ve Işılak Z., 2011. Hava kirliliği ve kardiyovasküler sistem. TAF Preventive Medicine Bulletin, 10: 97-106.

Marcus, C. 2015. Tree canopy assessment city of Atlantic Beach Florida, Legacy Arborist Services Tallahassee, FL, p. 8.
MEA (Millennium Ecosystem Assessment). 2005. Ecosystems and human well- being: a framework for assessment. MA (Millennium Ecosystem Assessment). http://www.millenniumassessment.org/ en/Framework.html.

Moran, J.M. and Mogan, M.D. 1994. Meterology: the atmosphere and the science of weather, NY Macmillan College Publishing Company.

McNeil, J. and Vava, C. 2006. Oakville's urban forest: our solution to pollution, Town of Oakville Parks and Open Space Department Forestry Section, p. 67.

Nowak, D.J. 2000. The interactions between urban forests and global climate change. In: Abdollahi KK, Ning ZH, Appeaning A (eds) Global change and urban forest. GCRCC and Franklin Press, Baton Rouge, LA, pp. 31-44.

Nowak, D.J., Hoehn, R.E., Bodine, A.R., Crane, D.E., Dwyer, J.F., Bonnewell, V. and Watson, G. 2013. Urban trees and forests of the Chicago region. Resour. Bull. NRS-84. Newtown Square, PA: U.S. Department of Agriculture, Forest Service, Northern Research Station. p 106.

Jacobs, B., Mikhailovich, N. and Delaney, C. 2014. Benchmarking Australia's urban tree canopy: an 1-tree assessment, prepared for horticulture Australia limited by the Institute for Sustainable Futures, University of Technology Sydney, finalreport_140930.pdf, p. 49.

Phillips, D., Burdick, C., Merja, B. and Brown. N. 2013. Urban forest ecosystem services: a case study in Corvallis, Oregon. Presented at Ecological Society of America, Minneapolis, MN, August 04 - 09, 2013.

Rogers, K., Jarratt, T. and Hansford, D. 2011. Torbay's urban forest assessing urban forest effects and values - a report on the findings from the UK I-tree eco pilot project, Treeconomics, 46p. ISBN 978-0-9571371-0-3.

Rogers, K., Sacre, K., Goodenough, J. and Doick, K. 2015. Valuing London's urban forest results of the London I-Tree eco project, Hill \& Garwood Printing Limited, 84p. ISBN 978-0. 9571371-1-0.

Seed Consulting Services, 2016. Tree ecosystem services assessment, Ridge Park. A report prepared for the City of Unley, South Australia, 94 p.

Smith, W. H. 1990. Air pollution and forests. New York: Springer Verlag. 618 p.

Spirn, A. W. 1984. The granite garden: urban nature and human design, NY Basic Books, p. 334.

Steiner, F. 2011. Landscape ecological urbanism: origins and trajectories. Landscape and Urban Planning, 100: 333-337.

USDA. 2008. United States Department of Agriculture and Forest Service. I-Tree User's Manual. www.itreetols.org/resources/ manuals/i-Tree\%20Eco\%20Users\%Manual.pdf, Accessed May, 192016

Yatkın, S. ve Bayram, A. 2007. İzmir havasında partikül madde kirliliği: ölçüm ve değerlendirme, Dokuz Eylül Üniversitesi Mühendislik Fakültesi Fen ve Mühendislik Dergisi, 8 (2): 15-27. 